\title{
Value Network Embedding Choice of Strategic Emerging Enterprises, Cognitive Dissonance and the Loss of Business Performance
}

\author{
BU Huabai ${ }^{1, a}$, BU Shizhen ${ }^{2, b}$ \\ ${ }^{1}$ Hengyang Normal University, Hengyang 421008, Hunan, China \\ ${ }^{2}$ Hengyang Normal University, Hengyang 421008, Hunan, China \\ aemail:buhuabai@163.com, bemail:bushizhen@163.com
}

\begin{abstract}
Keywords: Value network embedding choice of strategic emerging enterprises; Cognitive dissonance; Loss of business performance

Abstract. Under the background of "Internet +", strategic emerging enterprises must make themselves embedded in the enterprise value network to gain sustainable and healthy development, but it is difficult for decision maker to make the embedded choice effective. From the perspective of "cognitive dissonance" and "non-economics", this article analyzed the reasons why the value network embedded option induced the loss of business performance in strategic emerging enterprises and the countermeasures to reduce loss, so as to provide theoretical support and method guidance for reducing the loss.
\end{abstract}

\section{Introduction}

Cognitive research is an important research orientation in the field of international entrepreneurship in recent years, which has positive significance for a more comprehensive understanding of the entrepreneurial process. Entrepreneurial cognition can be defined as "the cognitive structure used by people in opportunity assessment, business creation and growth for Evaluation, judgment or decision-making"[1]. Our group study also found that when the new entrepreneurial ventures are in the process of ongoing selection embedded value network, entrepreneurial cognition of entrepreneurs will have an impact on decisions behavior of value network business.

Consulting the relevant literature shows that Mercer Adrian Slywotzky was the first one to put forward the concept of the value network in 1998. Then Prabakar Kathandaraman and David T. Wilson further deepen the concept of value network put forward by Mercer Adrian Slywotzky into a structure model of it $^{[2]}$. This structure model analyzes the network structure relationship between competitors, complementary, suppliers and vendors as well as the interrelation between the value creation, distribution and exchange in the value network. We can learn from this model, the enterprise in network node will affect the path and the quality of the resource acquisition due to different positions in the value network, which ultimately affect the Entrepreneurial Performance.

After reviewing the relevant literature, according to our research found that there are no special literatures focusing on how to increase the effectiveness of the new emerging strategic enterprises' value network being embedded in trade-off decision. Therefore, this article will investigate how to increase the effectiveness of the new emerging strategic enterprises' value network being in trade-off decision from the perspective of cognitive biases, so as to provide theoretical support and method guidance for the sustainable development of the entrepreneurship.

\section{Analysis of the occurrence of the cognitive dissonance of value network embedding choice of strategic emerging enterprises}

Modern cognitive psychologists generally believed that the cognitive process is essentially a process of information processing. But in this process, the question of human race, there is no unified view on the question that the human race is perceptual or rational in academia. J.Bentham and H.H.Kelly think people are rational, so according to their point of view, we could infer that the decision made by the new emerging strategic enterprises when they are setting in the value network should be rational.

Nevertheless, as we all know, we need to at least meet two premises to have a rational thinking 
for the option of Strategic emerging enterprises value network embedded. Firstly, the decision makers of emerging enterprise must have complete and accurate option information of Strategic emerging enterprises value network embedded; Secondly, they must have resources to processing the information.

However, the emerging value network enterprise's management environment have the complexity, dynamic and uncertainty and decision makers in the enterprise have the limitation of the ability and energy, which make the above two conditions difficult to completely satisfy in real decision-making of emerging enterprise. Consequently, it is difficult for decision makers of emerging enterprise in the process of cognitive to make rational decisions in the full sense, but they will try to find a shortcut of business decisions to simplify the complex entrepreneurship problems which the enterprise decision want to be solved.

We call the phenomenon cognitive biases of decision make that decision makers make mistakes judgment according to a certain phenomenon or information to event or other people. According to the decision maker using sample in different ways, cognitive biases can be used to divide the heuristic cognitive bias and framing cognitive biases. Now we analyze occurrence of heuristic bias and framed bias induced by the choice of Strategic emerging enterprises embedding value network.

Most studies of decision usually assume that different individuals tend to have similar ways of making decisions. However, some studies have found that entrepreneurs of the small and medium-sized enterprises like using heuristics more than managers of the large enterprises. Heuristics can make the entrepreneurs quickly understand the uncertain and complicated situation, and can also lead to preview orientation, new opportunities, perception, fast learning, non-traditional explanation, etc. ${ }^{[3]}$. Some researchers even argue that if there is no heuristics, we may never make many business decisions ${ }^{[4]}$.

On the other hand, heuristics may also produce cognitive errors. Baron points out those he entrepreneurs may be more susceptible to cognitive errors ${ }^{[5]}$, because of the emotional injection, counter-factual thinking and planning fallacy, self-serving bias, self-justification, etc. At the beginning of the entrepreneurship, decision makers' strategy to solve this complicated selection of value network embedded is usually based on the algorithm and heuristic which are the two of the most basic ways. Algorithms mentioned here refer to selectors of the value network embedded who rely on general rules to solve the actual problem. It can accurately indicate the value network embedded selection steps of the strategic emerging enterprises, is established on the basis of rational decision makers.

Heuristics is a method that the chooser of value network embedded depends on experience to solve the actual problem of value network embedded selection. It is based on irrational sensibility of decision maker. But it is difficult to have their own algorithms for this problem, such as the problem of complex dynamic environment which must be faced when Strategic emerging enterprises make decisions. So, in general, more selectors of value network embedded used heuristics.

The heuristic dissonance caused by representative heuristics. Kahneman, Slavic and Tversky think that under the condition of uncertainty, people will focus on the similarity of one thing with another thing, and depend on the similarity to infer the relationship between them. Cognitive psychologists call this inference process "representative heuristics". when decision makers of newly emerging enterprises use representative heuristic to determine problem, they like divide model of the value network embedded choice into several typical categories, such as structural embeddability, relational embeddability and so on .On choosing value network embedded, decision makers overemphasize the importance of this kind of typical categories, and ignore the possibility of other potential model, such as politics embeddability, culture embeddability etc.

Newly emerging enterprise making simple embedded decisions, the short cut on this assumption is valid. However, When making complex embedded mode decisions, sometimes this assumption may lead to severe cognitive deviation, and lead to the loss of enterprise business performance, such as insensitivity of decision makers to the sample size of decision, " ignorance of decision sample size", etc.

The heuristic dissonance caused by availability heuristics. According to rule of cognitive 
psychology, decision makers tend to based on availability degree of the object or event in the consciousness or memory to evaluate the relative frequency of occurring. Those which easily perceived or recall judged to be object and event occurring more often, and regarded as the basis of decision making. This method is called the availability heuristics. For this kind of prediction based on availability degree, it may lead to cognitive biases.

As we know, in the operation environment of new ventures, factors influencing the choice effectiveness of enterprise value embedded are various and very complex. Some evidence factor are easier to obtain than others, therefore, the decision makers will actually make decisions according to the partial evidence factors which are easy to obtain, so decision samples are often lack of representation. Any sampling lack of representation or preferring sampling both can cause cognitive biases of decision makers, and loss of decision-making performance.

In addition, cognitive biases can also cause by imagery of decision makers in new emerging expertise. For example, if on making decision, difficulties of embedded choice are easy to be vividly described, so, the selection of embedded mode looks risky. On the contrary, if difficulty of those is not easy to describe, the risk of new emerging expertise selecting embedded mode may be underestimated in general. Therefore, in the embedded choice's decision of new emerging expertise, imagery can also cause decision-makers of deviation, damage entrepreneurial performance of new emerging expertise.

The heuristic dissonance caused by heuristic simplification. According to cognitive psychology, the typical heuristic simplification can be subdivided into narrow framing effect, belief correction memory consolidation effect and attention and leisurely treatment effect and so on three types of effect. Here are three types of effects.

The heuristic dissonance caused by narrow-framing effect. Narrow framing is also a kind of typical heuristic to simplify, also causes the start-up policymakers cognitive biases. In accordance with the "narrow framing" principle, decision maker of Start-up have a tendency which have cramped angle and thinking isolation when analyze how to embed value web of new strategic industries. While under their limited cognitive ability, this tendency is likely to happen.

The heuristic dissonance caused by belief correction-combination effect. Belief correction combined affects a cognitive bias caused by conservatism. Under suitable situation contrary to rational Bayesianism which adjust their prior beliefs on time when face with new situation in new strategic industries, they usually underestimate the importance of new situation in new strategic industries. Whatsoever more important this new situation to choose how to embed value web, bigger disparity made between sense adjustment and rational adjustment . The main reason is over reliance to signal strength or lace of reliance to signal importance when new strategic industries choice embed mode, what probably induce heuristic deviation and finally effect entrepreneurial performance.

The heuristic dissonance caused by attention, memory and leisure treatment effect. According to attention memory and leisurely treatment effect, normal Start-up decision maker just have restricted attention, memory and information processing which compel them use partial information to concentration analysis. Besides that , on the basis of cognitive psychology Principle, some maker's unconscious association also lead to tendency when chose information. Therefore we know that attention memory and leisurely treatment effect induce cognitive bias.

According to the results of the study of psychologists, if value network embedded selection information has features which is attract the attention of entrepreneurs and triggered entrepreneurs produce association to memory, it is have active effects. As common fairs was always repeatedly noted and reported, entrepreneurs more likely to recall them, them easily be judged as very common situation to deal with, thus net effect appear. No matter active effects or net effect entrepreneurs are having heuristic deviation.

The heuristic dissonance caused by anchoring and adjustment heuristics. During judging process, people would like to have anchoring effect with initial information. There are two types of deviations caused by anchoring. 
Dissonance caused by insufficient adjustment. In a psychological test, it remand object who to be measured to estimate result of a group of numbers. The numbers of the first set of object is $8 \times 7 \times 6 \times 5 \times 4 \times 3 \times 2 \times 1$, and the second is $1 \times 2 \times 3 \times 4 \times 5 \times 6 \times 7 \times 8$, finally mean of the first one is 2250 , while the second is 512 , there have a big difference (right is 40320). Why there have such a big difference just of different range?

Psychologists think it because objects have anchoring effect at beginning, and then adjustment is not enough to achieve due level, all of these lead to anchoring adjustment deviation. When select embed new strategic industries value web, the most underestimate value of competitive strength also effect enterprise strategic positioning finally effect final embed mode, higher or lower all likely make deviation of enterprise strategic positioning.

Dissonance caused by evaluation on jointed and separated events. In another psychological test, objects remand wager on two fairs .The first type event is a simple event, from a bag which with $50 \%$ black balls and $50 \%$ red balls to get a red one, the probability is $\mathrm{P}=0.5$. The second is a joint event, From a bag which with $10 \%$ black balls and $90 \%$ red balls to continuous get7 red balls with can be put it back, the probability is $\mathrm{P}=0.48$. The third is a separate event, from a bag which with $10 \%$ red balls and $90 \%$ black balls to get 7balls with can be put it back it require at least one red , the probability is $\mathrm{P}=0.52$.

When wager on simple event and joint event, most objects wagered on joint event $(\mathrm{P}=0.48)$ not simple event $(\mathrm{P}=0.5$ ), although probability of a simple event is bigger. When wager on simple event and separate event, most objects wagered on simple event $(\mathrm{P}=0.5$ ) not separate event $(\mathrm{P}=0.52)$, although probability of separate event is bigger. This selection mode show that people prefer overestimate probability of joint event and underestimate simple event separation event, what will produce judgment bias. When chose embed mode of new emerging enterprise value network, overestimate probability of joint event will make decision be inclined tomulti layer structure embedding and mufti relational embedding.

"Frame" is a form of things that are used to describe decision problems, but many of them are not transparent. When the enterprise decision makers have a view of the enterprise value network, the decision results will be largely dependent on the frame.

The deviation of the cognitive and judgment is defined as the deviation between the frame and the frame. The deviation of the value network is determined by the background of the decision making. The background is mainly four kinds of situations.

The frame dissonance of the choice of value network embedding caused by comparison effect. Plous (1993) made a simple "hot water, warm water" contrast test, it was found that each hand had a "contrast effect", but the two effects were the opposite. The contrast effect was different, and the choice of the value of the new business value network was different.

The frame dissonance of the choice of value network embedding caused by the halo effect. The so-called halo effect, is in the process of interpersonal communication, one aspect of the characteristics of people showed up, other characteristics, thereby causing the interpersonal cognitive disorder. The halo effect is a tendency to evaluate "over-generalization", which can achieve "Aiwujiwu" degree, the error is: first, seize the individual characteristics of strategic emerging enterprises, used to the individual and the general, like to point to the surface; on the basis of one-sided viewpoint, second, had no internal connection features of some strategic emerging enterprises together, that characteristics of the strategic emerging enterprises will have another feature; third, said it was all certain strategic emerging enterprises say, strategic emerging enterprise bad all negative, this is a kind of subjective prejudice dominate the absolute tendency.

Halo effect inspiration to new venture decision makers, decision makers in the choice of the value net member, don't be confused by a characteristic factors of some enterprises, to an objective evaluation of the comprehensive value of enterprise network members, try to avoid and overcome the side effects of the halo effect.

The frame dissonance of the choice of value network embedding caused by dilution effect. Arenson thinks, although have more information sometimes will indeed help, but at the same time, it 
will "dilution effect" by changing the way we think about things, neutral and non-relevant information easier to reduce the judgment or impression. The experimental data show that the grasp of the existing problem of non-relevant and non-diagnosis fault information to produce a dilute the role of relevant information, leading to decreased effectiveness of the relevant information. Dilution effect for new venture decision makers can clearly grasp the information of strategic emerging enterprise value net embedded mode choice decision is reliable and valuable. The information is unreliable or reliable but no value.

In addition, Gross believes in his agent's manual that people prefer a type of frame, which is called "optimistic editing”. However, decision makers often lack a stable preference order. They can also influence the choice. We know that the decision maker's decision can be caused by the effect of "optimistic editing”.

In addition, the primacy and regency effect are psychological factors that cause biases in individual cognitive, but conditions that the individual information works on cognition are different. If two kinds of information about someone are perceived in a row, people always tend to the former information, and form a deep impression, which is the primacy effect. If people know someone information first, and know the second after a long time, the second will be the latest information. The latest information will leave people a deep impression, which is the regency effect. Whether it is the primacy effect or regency effect, they will lead to the framing error of entrepreneur.

\section{Avoidance of the dissonance of the value network embedding and the loss of business performance}

So far, we have discussed the cognitive bias errors of Entrepreneurial Performance loss which caused by the strategic new business embedded value network. So, how to analyze the reason of causing cognitive bias errors by Strategic emerging enterprises embedded value network, so as to avoid performance loss? We believe that there is at least three "myth" need to avoid.

Facing the objectiveness of cognitive bias errors caused by Strategic emerging enterprises embedded value network, avoiding thinking myth and reducing entrepreneurial performance loss in terms of ideological decision

According to the theory of the Nobel economic prize winner H.Simon, the decision theory of economics does not take the cognitive limitations of Strategic emerging enterprises decision makers into account and their humanity is assumed to be "rational". However, it is just effective enough for Strategic emerging enterprises embedded value network option in reality, which means that the information processing system of the new Strategic emerging enterprises decision-makers just need to be satisfactory, without searching all the possible choices indefinitely. The cost of information searching and processing takes a lot, if you insist on "unlimited search", it will inevitably make the cost of information search is greater than the profits of information search, causing searching more harmful.

And at the same time, due to the existence of the "dilution effect", more diagnostic information may increase the cognitive deviation of decision makers, and affect the quality of enterprise's decision from the opposite side. So, we should face the objectiveness of cognitive bias errors caused by Strategic emerging enterprises embedded value network in terms of ideological decision, respecting the limitations of human knowledge, adhering to the principle of moderation to not fall into the trap of "maximize" searching and reducing the loss of new Strategic emerging enterprises business performance.

In strategic enterprise value network embedded on select sample sampling, beware of over-sampling bias, to avoid "sampling errors" , to reduce entrepreneurial performance loss

Faced with the limited environmental complexity and uncertainty as well as human capacity ,human meta cognitive monitoring ability is always inadequate the new venture decision makers mental computing power of the sample data and a lack of ability to correct the potential bias, this makes them even though aware of the existence of sample bias, and he cannot eliminate them. But this cannot be our reason to ignore reduce sample bias in the sample sampling reality, we must 
prevent excessive deviation of the sample, to avoid "sample errors", improve the quality of decisions, reduce entrepreneurial performance loss.

In Strategic emerging enterprises embedded value network selection process, to address people' s irrational behavior, to avoid misunderstanding of human nature, to reduce the loss of business performance

Psychologists through experimental observation and empirical studies have found that people tend to trust their own ability to judge too much, thus the performance of overconfidence in behavior, strategic and emerging business decision-makers there is also the phenomenon of overconfidence, the existence of this phenomenon to them embedded value of the selected information processing network, three things:

First, over-reliance on their own to collect the value of the network embedded information collected contempt even deny others the value of the embedded information network; Secondly, when the value of the filter mesh is embedded in a variety of information, they focus only on those that do not hurt the confidence of value network embedded information; Finally, once formed a strong belief embedded assumptions will often misinterpreted some additional evidence favorable to the hypothesis.

Obviously, moderately confident will help improve and optimize enterprise value embedded in the selected network, but overconfidence is a non-rational behavior will affect the quality of their embedded value network of choice, therefore, the strategic new business embedded value network selection, humanity must strive to avoid errors, in order to enhance the quality of their decision-making, reduce entrepreneurial performance loss.

\section{Acknowledgments}

The research of paper is supported by Philosophy and Social Science Foundation of China (12BGL005); Education Ministry Philosophy and Social Science Foundation of China: Embedding, the consequences of strategic positioning and growth-based on intelligent network of logistics companies” (12YJA630004).

\section{References}

[1] Hailei Li, Wen Zhang: submitted to Journal of Shandong Normal University (Humanities and Social Sciences) (2014).

[2] Mitchell, R.K., Smith J.B., Morse, and E.A: submitted to Journal of Entrepreneurship Theory and Practice (2002).

[3] Gavetti. G, Levinthal. D: submitted to Journal of Administrative Science Quarterly (2009).

[4] Busenitz, L.W., Barney, and J.B: submitted to Journal of Business Venturing (2007).

[5] Baron, R.A: submitted to Journal of Business Venturing (2013). 